\title{
Connections between Neo-Liberalism, Neo-Conservatism, and Critical Democracy in Education
}

\author{
Sirous Tabrizi \\ University of Windsor, Windsor, Canada
}

\begin{abstract}
In a global society, where an emphasis on equality and social justice is important, equality of opportunity is of high importance especially for minorities. Policy makers are often influenced by ideology, and this is true of those in education too. Two currently popular ideologies are neo-liberalism and neo-conservatism. Although both seek to create opportunities for citizens, they use slightly different means and their impact on education may hamper creating positive outcomes for citizens. In particular, their emphasis on marketization and privatization of the education system can be potentially problematic for the development of critical democracy in a society. This paper will examine how neo-liberalism and neo-conservatism influence attempts to implement critical democracy in education, and why an emphasis on critical democracy regardless of the underlying ideology is better for education.
\end{abstract}

\section{Introduction}

As the world is becoming more heavily globalized, education systems are slowly changing and adapting accordingly. A properly functioning globalized society requires the harmonious cooperation of multiple diverse groups, which suggests that topics such as equality and social justice are of great importance. Hence, an education system for a globalized world needs to include some preparation of students for potentially engaging with others who have a very different background and set of opinions.

Different schools of thought have emerged to address this new kind of educational need, of which three will be examined in this paper: neo-liberalism, neo-conservatism, and critical democracy. Each of these schools attempt to train students for effective performance in a globalized society, but they differ quite a bit in terms of how this educational should occur, the policies involved, and the role of government and economics. However, in this paper greater emphasis will be placed on how these different schools encourage and enable different groups to become educated. It will hopefully become clear how neither neo-liberalism nor neoconservatism are sufficient for effectively educating all people in a country to become more active and capable global citizens.
In the next section below I will provide a brief background of the three schools of thought. After that, a longer discussion will be made about the educational implications of each school. Finally, this paper will end with a short summary and conclusion.

\section{Literature review}

This section will briefly discuss the three main concepts of this paper: neo-liberalism, neoconservatism, and critical democracy.

\subsection{Neo-liberalism}

Proponents of neo-liberal ideology argue that open, competitive and unregulated markets that have been liberated from all forms of state interference "represent the optimal mechanism for economic development" [3]. The paradox of neo-liberal ideology, continue Brenner and Theodore, is that while it emphasizes decentralization of administration to local and private institutions, in practice, Neo-liberal policies and practices actually involve "coercive, disciplinary forms of state intervention in order to impose market rule upon all aspects of social life" [3]. In education, the Neoliberal agenda manifests itself in closer linkages between schools and businesses as well as the implementation of "free market" reforms, such as school vouchers, into education policy $[7,11]$.

\subsection{Neo-conservatism}

Neo-conservatives are usually guided by a vision of a strong state that asserts control over knowledge, culture, and the body. They seek a return to a romantic past where "real knowledge", morality, and a supposedly stable social order existed. In education neo-conservative manifest in national and state-wide testing and curricula, content standards, the heralding of western canon of knowledge, a relatively uncritical patriotism, and moral education [7, 11].

Neo-conservatism has its roots in American politics. It is based on a version of US Conservatism, itself possessing tenets of neo-liberalism. Neoconservatism promotes traditional values to the extent that this party rejects individual rights. Rights for Neo-conservatists do not supersede 
considerations of state; on the contrary, the public good justifies the state in setting aside the liberty of persons to live their life as they choose. Apple [11] writes that Neo-conservatism supports a limited welfare state in favor of low taxes and a free market. According to this theorist, neo-conservatives are still willing to interfere for overriding social purposes even while rhetorically being supportive of free markets. They accomplish this by setting private enterprise loose; from which, the state needs to be strong in teaching "correct" knowledge, norms, and values.

As such, education is the major emphasis for neoconservative thought. The state has an important duty, through education, of reinforcing specific cultural, religious, national, and ethnic identities [16]. However, the state is not necessarily a supplier of education but rather an agent that regulates the educational content (ideas, materials, perceptions, etc.). History, language, and religion are the educational subjects which receive the most regulatory focus due to their strong influence on identity generation. As a result, the debate surrounding these topics becomes very heated. History is the most important of these subjects though, due to the influence of history education in conveying particular identities and ideas about the past and future [12].

\subsection{Critical democracy}

Although both neo-liberalism and neoconservatism can be foundational ideologies for educational systems in democracies, what is meant by democracy can be radically different [20]. In one case, democracy can be defined in terms of individual and civil rights and a representative government [20]. In another case, it can be defined in terms of choice or even as consumer-like choices [8, 11]. In contrast, critical democracy is defined as an ideal that is committed to social justice, equity, diversity, reasoned choices and public participation [14]. Alternative definitions exist, though these contain similar or overlapping themes and principles such as equality, inclusion, mutuality, discussion, debate, critical-mindedness [11, 14, 20].

Education from a critical democracy perspective is intended to "foster the development of critical, engaged citizens committed both to creating a robust participatory and pluralistic democracy and to pursuing justice" [13]. Students are thus encouraged to be open to different viewpoints, to value these differences, and to recognize how an issue can be understood from different perspectives [14]. This requires students to learn respect for the opinions and ways of life of others, especially those that may different from accepted social norms, provided these differences do not lead to the harm of others [17]. In doing so, they also learn to respect diversity and that all individuals have an equal standing [1].

However, simply learning these differences and respect is not enough. Students also need to learn how to engage in respectful dialogue with others who may have drastically different views [1]. The purpose of these dialogues is to encourage the flow of ideas so that students may become as informed as possible [7], for students to become comfortable with being exposed to new or different ideas [14], and to encourage proper handling of conflict [13]. Furthermore, to properly engage in such dialogue students need to learn how to think critically $[8,13$, 14].

The overall intent behind such education though is to encourage an attitude of commitment to community and active participation in the present life of the community so as to shape its future form toward the common good [7, 8, 14]. Such participation requires discussion about conflicting beliefs, determining what is the best interest of the community, and exploring these conflicts and tensions so as to understand the real purpose, intent, and needs behind such differences $[8,13,17]$.

Educators within a critical democracy education require a critical perspective, and must demonstrate concern for human digital and minority and individual rights [7]. It is necessary for them to approach students as people who can contribute to the inquiry that occurs in the classroom, and to remain aware of any hidden agenda within their own curriculum [8]. In addition, collaboration between teachers and researchers is encouraged for the purpose of creating equal educational opportunities through policy, pedagogy, and curriculum [4]. The role of public school thus becomes not only a place for fostering desired qualities in students but also as an incubator of social justice projects.

\section{Discussion}

In general, neo-conservatives agree with neoliberals on the importance of free markets, free trade, corporate power, and elite government [18]. Namely, neo-liberalism and neo-conservatism focus on markets, the size of state (generally they prefer a small state), and freedom of private enterprise. Neoconservatism, however, focuses on traditional values [11] and is much more inclined to combine their hands-off attitude toward big business with intrusive government action for the regulation of the ordinary citizenry in the name of public security and traditional morality. In the context of foreign affairs, neo-conservatives promote extensive use of both economic and military power, claiming as their motivation the promotion of freedom, free markets and democracy [18].

Critical democracy tries to establish social justice, equality, diversity, participation, cohesion and 
freedom of choice for all citizens. These goals are for all areas of society such as health, education, and so on. Critical democracy has a sensitive role to promoting the education system because it is a major public asset. For example, in Canada public expenditure on education exceed the billions every year. Not only is the education system a major public asset now, but is likely to become more important in the future [4]. In this sense, Connell is proposing that education is a moral process when he says that "teaching has been described as a 'moral trade'... this is profoundly true" [4].

\subsection{Marketization}

Two major areas of influence that have been associated with either neo-conservativism or neoliberalism include marketization and privatization. Although these terms are often used interchangeably, there is a subtle distinction between them [5]. Marketization typically refers to the creation of "quasi-markets" for state-funded services [5]. In education, for example, marketization involves changing the degree of school autonomy, parental choice or influence, public accountability, and/or governmental regulation. In one case then this could simply involve optional courses or materials offered by a school that parents would have to pay for, but it represents parental choice since it is not necessary for student graduation. At a broader level though, it involves allowing a school to determine the curriculum, courses, and materials that it offers. Ideologically speaking, the school would determine this based on market needs, though this market could be anything from the global circumstances to what students express interest in taking.

Both neo-conservative and neo-liberal ideologies support marketization, but for different reasons. Neoconservative support is for using these new markets to reduce governmental control, size, cost, and regulation. However, they are less willing to remove governmental regulation over educational content, because this content is the primary means by which traditional and national values can be promoted [11]. Neo-liberal education reformers' have an enhanced market system at the heart of their vision; marketbased education system providing good conditions to enable students to achieve new knowledge with a better method [15, 19]. Education policy would therefore emphasize market-driven schools, in which students and parents (the clients) are given the opportunity to choose for themselves the kinds of educational 'services' that they feel are best and educators can select the services and products that best meet their needs. Advocates of this vision claim that the freedom to choose can be a desirable practice that is consistent with democratic ideals.

However, marketization can be particularly problematic in terms of critical democracy due to its influence on student viewpoints. Encouraging market influence in education means that the source of the choices available to parents and students are often external. In other words, even though parents and students have choice regarding the materials available or the courses offered, these choices are based on external demand: the students are likely influenced by parental desires, parental desires are often geared toward 'superior professions' in terms of economic and lifestyle possibilities (e.g., medical doctor, engineer, lawyer), school programs are offered based on what parents are willing to pay for. This can easily occur at any level of education, depending on the strength of parental desire and the options available for students. If students must achieve a certain potential (i.e., grade, course completion, experience) by mid-elementary in order to guarantee success in the desired field, parents will push for that even though many other options might be available.

One result is that higher demand for the popular courses can lead to higher competition, as the capacity for these courses and materials may be too low. Higher competition often leads to higher quality of the product. For instance, students in these high demand courses learn to work harder and more diligently, and this can carry over into their life outside of school. This is not always the case however, and it can also lead to significant stress and other adverse effects. In addition, higher competition can also result in a lowering of the quality of the alternative programs, since funding (i.e., parental support) is moved to the more popular ones. The students who enter into these programs may be less capable than their peers, but their contributions to society may also be lessened due to lower support from the schools themselves. In practice, marketization of schools has not yet reached the stage where this is a serious problem [5] primarily due to state control over a core curriculum (a neoconservative influence).

Another result is that students are not exposed to a variety of viewpoints in terms of professions, concepts, lifestyles, and theoretical models. This occurs when the students are required to take only the material necessary for their chosen field, regardless of this choice. When certain fields are more popular to parents, students are more likely to enter into those fields. Thus, not only are students isolated from alternative views but they are also disproportionately biased in the views with which they are familiar. As education systems grow in marketization, and fewer parents support alternative professions, the schools will respond and reduce the quality or offering of these alternatives. From a neoliberal perspective, this is to be expected [11] and a result of market forces but from a critical democracy perspective this results in a narrowing of the 
students' mind, limits their exposure to alternatives, and hampers their ability to understand others [8].

Finally, it should always be kept in mind that students eventually leave the school and become reintegrated into society. One effect is that they become parents and could continue or further influence market demand in such a way that a harsh cycle is formed. However, alternative market forces could intervene and prevent this (e.g., collapse in market value of a previously popular profession). Another effect is that the students in the popular programs vastly outnumber those in the alternative programs. Furthermore, these students are presumably have a higher income-earning potential, since that is why their programs were popular in the first place. Their increased number and wealth means these individuals have a greater influence on the school market than others, but also a greater influence in other areas of society (e.g., government policy, global markets, etc.). The goal of critical democracy to engender open-mindedness, responsibility, and social justice would greatly enhance the positive influence these students could have despite their increased numbers. Hence, marketization here is not necessarily bad for critical democracy but has to potential to limit its effectiveness.

\subsection{Privatization}

In contrast to marketization, privatization refers to the transfer of services from the public to the private sector [5]. This transfer can be gradual or immediate, and partial to various degrees or entirely made private. Although the stereotypical view of privatization in education is the wholesale removal of public funding from schools, in reality it involves a gradual movement away from total funding to privately-funded yet state-subsidized and regulated bodies [5]. Both neo-conservative and neo-liberal ideologies support privatization for much the same reason as marketization: to reduce governmental control, size, cost, and regulation.

Supporters of privatization believe that a private school system gives opportunities to the lower class of society, who normally use the public school system. A private school education can also reduce the number of students in the public school system, and teachers can therefore allocate more time with students. Additionally, such a system would reduce the educational costs for government budgets, allowing for investment in other parts of society. From this perspective, private schools give students more opportunity and this freedom of choice does not conflict with principles of social justice or equality.

Opponents of privatization though suggest it has a negative effect on the education system. This is because private schools are able to hire teachers who have higher knowledge and experience, consequently leading to inequity in the education that students may receive. Privatization will transfer a higher educational cost to families. This higher cost may be acceptable for wealthy classes of citizens. Middle class citizens may also want to send their children to private schools, but it may become too expensive or difficult for them. As such, the higher cost creates a barrier to the education that can only be overcome by a minority of people in the society, and this is also considered an example of inequity. This difference becomes worse when the government wants to encourage privatization through offering financial support. In doing so, the government actually takes funding away from public schools, furthering the difference in quality between public and private schools. Although such support may go against neoliberal and neo-conservative ideas of privatization, it can still be the approach taken when government policy-makers want to quickly and strongly encourage privatization. Thus, opponents of privatization conclude that it is a fundamental cause of inequity and social injustice in society because family income becomes too strong of a factor in determining the quality of education that students receive.

\subsection{Policy making}

Although critical democracy can be pursued at a policy level in government, neo-conservatism and neo-liberalism have a greater history of influencing policy. Key players involved in the policy-making process include governmental (Legislature or House of Assembly, Cabinet, Bureaucracy, and Privy Council Office) and non-governmental (interest groups, mass media, community, board of directors, regional boards, lobbying groups, and individuals) entities. The different stages of policy development include formulation, implementation, and evaluation. There are also some fundamental issues which guide these processes such as: policy as text and discourse, policy as multi- dimensional, policy as value- laden, policy as existing in context, and policy as state activity (see [19]).

Taylor and colleagues [19] write that "even without any obvious ambiguities in a policy text resulting from competing interest, there will be no single interpretation of a policy document" (p. 50). These theorists went on to quote some stories about people with different jobs, all of whom were under the pressure of certain policies. In this context, we can observe some commonalities across systems and groups: policy implementation can never be achieved in a vacuum since policies are part of social environment, and policies tend to be ignored, resisted, contested, or rearticulated to suit local circumstances; and the idea of community participation in decision making and equality of 
education opportunities are flourishing. This is to say reactions and understanding to policy are often not linear or rational; there are complex and multiple factors influencing perception and therefore implementation of policy initiatives.

Several instances of the complexity of policy making come to mind in relation to the Ontario context where some policies have been subjected to interpretations quite different than originally intended by the policy makers. The EQAO tests, for example, were ostensibly developed to assist schools in better developing programs to increase student achievement and also to serve as an accountability measure. From the onset of articulation and formulation, and even today, arguments abounded about the 'hidden' agendas of this tests; the competence of schools, teachers and boards are assessed through these tests. The ministry sees this policy as serving the needs of the education system, tax payers and some parents take it as justification and investment and principals and teachers see it as a flawed, over-emphasized and oppressive system that seriously derails their best efforts at improving student learning.

The work of Ball [15] and Taylor [19] clearly allude to policy making as a value-laden, complex and multi-faceted process. Moreover, as Taylor and colleagues aptly posit, policy is interpreted differently by different individuals and groups. Individual and group ideals and values would influence policy interpretation and reaction, and this will resultantly affect the level of commitment brought to policy implementation. It therefore stands to reason that the values and assumptions policy makers consider hold dear will substantially influence the nature and scope of policy reforms. It is important to point out that there is significant overlap in terms of the influence of these movements on policy formulation, interpretation and implementation because initial values and tenets of each will necessarily follow into and shape the different development stages of the policy making process.

In recent years, Neo-conservative critics of U.S. higher education have called for a return to core humanities curricula that would emphasize the value of western civilization as the cornerstone of U.S. culture [10]. A neo-conservative agenda of policy reform thus emphasizes traditional values. The role of the state (a minimized state, private enterprise) here will be to maintain central control of education, standardizing and making explicit the correct knowledge, norms and values to be instilled. In the United States, for example, there is a panic over falling standards, illiteracy, and dropout rates; a fear of violence in school; and a concern over the destruction of traditional values. These have had a major effect and have led to attacks on teachers and teacher unions and to increasing support of marketization and tighter control through centralized curricula and national testing [11].

George Radwanski's call for a return to the teaching of core knowledge and skills in the Ontario curriculum came from a Neo-conservative lens. According to him, education policy designed for the new (twenty-first) century should equip students with the necessary specified knowledge and skills that would prepare them to successfully work in that era. The contents, structure and language of the Ontario Curriculum serves as an example of how neo-conservative ideals have influenced the curriculum and pedagogy of the education system.

As seen with Neo-liberalism and Neoconservatism, the ideals of critical democracy will impact the language and direction of the policy making process. These policies will seek to better the learning experiences of students, especially the especially disadvantaged so as to ensure that every child reaches his/her potential. Policy reforms will strive to take some action to redress social inequalities with the overarching goal of achieving social justice and equality (see [9]). To develop democratic outcomes links between learning, teaching and democracy are primary issues in education; these include issues such as critical thinking, classroom discussion between students and teachers, civic education, and student councils that promote particular skills, attitudes, values, and behaviors in students. This can result in helping students become active citizens, and can rejuvenate the larger democratic society [9].

\subsection{Example from Ontario government}

As an example of policy-based privatization and marketization in Canada, consider the Education Quality Improvement (EQI) Act from the Government of Ontario in the 1990's. This act focused on teachers, school boards, per pupil funding, and taxpayers and became important for teachers in the province of Ontario. It legislated that class size limits, teacher preparation time, administrative time, and the length of the school year would be set by the province and not through local school board negotiations with teacher unions. Teachers had to work hard and the government even increased the number of teaching days and the instructional time requirements, which resulted in reduced preparation time for high school teachers. In other words, teachers had to spend more time with students and they had to work with less time for preparation, not taking into account the quality of time spent with students, individually or in groups.

The ideas behind the EQI Act are set out in the Common Sense Revolution (CSR), the certificate that outlined major changes to a multitude of programs and services, peculiarly in education, that occurred when the Ontario Progressive Conservative Party 
was elected to office in 1995. This intent is also obvious in the legislation that was since coming to office by the government such as the Fewer School Boards Act and the EQI Act, as well as in its 1996 budget and prior economic and fiscal statements [21]. The CSR also adopted a policy of alignment that would impose a clear division of labor between the political leadership as policy makers and the public service as policy implementers. In general, the overall policy involved introducing a system in which all funding available to a school board and every cent raised for educational purposes was determined by the province. Elected trustees found themselves stripped of local taxing powers and their position reduced, through governance changes, to a consultative role in the education bureaucracy. The EQI Act centralized control over the amount of money to be raised for education and how that money was to be spent; the formulas would spell out how much money each local board would receive and what that money was to be spent on [6].

Initial discussion and resistance to the CSR in general, and the EQI Act in particular, started when the current leader of one of the opposition political parties leaked a copy of a draft of the deputy minister of education's performance contract. In this contact, the minister was directed to slash $\$ 667$ million from the schools' budget during 1998-9 [6]. After release of this document, the government confirmed the additional cuts, effectively undermining their earlier claims that there were no budget-reduction targets.

The funding formula had a critical effect in the situation of teachers in the province of Ontario, and it was a fundamental reason for the big strike in the North America in 1997. Before the strike, the government appeared to have the general support of the public and it expected the teachers to suffer a debasing defeat. However, what turned parents and other concerned citizens against the EQI Act was the discovery of the leaked performance contract draft. After the draft was leaked, the Ontario Premier Mike Harris and his education minister tried to convince the public that they had no specific target for further education cuts. But the leaked document exposed the real intent of the government, which was to find money to reduce income taxes, as it had promised it would do. The nearly $\$ 700$ million in proposed cuts would be equivalent to the amount of money the government would lose from reducing income taxes. At the time, it was estimated that the cuts would increase class size, even though there was already a law capping class size at 20 for elementary schools and 25 for high schools, and would ensure that government regulations would take precedence over legislation passed by elected representatives [6].

In an interview after introducing the EQI Act, Harris said, "There is more than enough money in the system: the problem lies in the fact that that it is not spent to improve the quality of classroom education." [6] In the Act, classroom and nonclassroom spending was supposed to be clearly defined. Classroom costs focused on teachers, supply teachers, learning materials, classroom supplies, staff development, library and computer use for classrooms, and classroom assistants. Nonclassroom costs included teacher preparation time, district consultants, school administrators and custodial services [6]. The Harris government introduced a fiscal formula to centralize funding control, believing that a centralized system can improve the quality of education. It was also believed that cuts to the number of school boards and trustees per board set out to punish large urban public school boards for what the Harris government deemed to be excessive spending [6].

However, the given formula did not provide sufficient funding for the basics of the system: the payment of teachers, principals, and the operation and maintenance of school facilities. Addressing these problems is not a simple matter of sending more money into the existing formula structure, because that structure itself reflects a vision for the school system that is at variance with the government's reform objectives. The main objective of the Harris government in designing the funding formula was financial: to control and reduce the provincial government's total financial obligation. The formula's success in doing just that provided much of the fuel for funding discussion [6].

The overall policy of the EQI Act had two opposing poles: the Harris government and the teachers. With the establishment of this policy and a reduction in education funding the Harris government could support its deficit funding. In other words, they could have more flexibility in taxation that would be a trump card for the next election. On the other hand, teachers were in a critical situation because they had to spend more time with students and even their parents, not the amount or quality of time spent with students individually or in groups in other words. Hence, the funding reduction from the budget had a direct effect on teachers' lifestyle. After the Harris government though this policy changed, and only teachers, students, and their parents have a bad reminiscence of this policy [6].

The funding formula was supposed to demonstrate that the system already had more than enough resources to do the job, and the Government claimed to be motivated by a concern for equity among students [6]. With these issues, the Harris government started to develop a centralization policy of monitoring costs and reducing the number of boards (and renaming them "district school boards") for the purpose of improving the education system. The funding formula of this policy had some inconsistencies and contradictions, such as a narrow definition of education and of the real role of schools 
in our communities. The formula is clearly designed to produce equality in funding regardless of circumstances or need, rather than equity [6]. Not only did this formula have difficulty in establishing equality between students but also the issue of equity was quite relevant: differences in race and class directly or indirectly factored into enrolment decisions in popular schools, often in ways that affected or led to segregation, social divisions, and school achievement.

It is widely believed that the CSR employed a clear mix of Neo-liberal and Neo-conservative principles [6]. The belief was that efficiency and accountability would attract the attention of taxpayers, and a series of educational policies (based in a climate that emphasized job creation, economic recovery, and renewed growth) were developed [22]. This included expanding corporate sponsorship of education, suppressing teacher compensation, levels of private ownership in school, and aligning school curriculum with the economy. The intention, it seems, was to privatize the education system in Ontario: "The Harris government intends to reduce the role of the state and create the maximum possible scope for the private sector. In addition, it wants the public sector to function in a more business-like manner." [21, p. 101] So too will policy development of the Neo-conservative agenda emphasize traditional values in setting standard curricula and instruction and developing programs of high skills, the curriculum (e.g. Ontario Curriculum) through state control such as the Ministry of Education. The EQI Act is also an example of control that focused on teachers, school boards, per pupil funding, and taxpayers. The state must actively mold people in order to make them virtuous; and among these virtues, sacrifice for the common good is paramount.

\section{Conclusion}

In creating an education system for a globalized society, critical democracy may be the best school of thought due to its emphasis on establishing equality and social justice in all sections of society. However, there is also some overlap and agreement between critical democracy and neo-liberalism in two main ways: freedom of choice and globalization.

Freedom of choice can empower and enable all ethnic groups in multicultural societies to strive, giving them opportunities that they might otherwise be denied. Hence, it is of great benefit to critical democracy. Freedom of choice though is also an intrinsic element of neo-liberalism, particularly as it relates to the free-market. The difference between critical democracy and neo-liberalism with respect to freedom of choice is in how they approach education. In critical democracy, education is seen as a service provided by the state to its citizens, whereas neo-liberalism sees education as a means for the state to affect future generations [2]. The first emphasizes the individual aspect of education, while the second emphasizes the social or collective aspect of education.

More importantly, both critical democracy and neo-liberalism place a strong emphasis on globalization. In neo-liberalism, globalization extends the range of the free market to ideas, allowing ideas to compete such that the best ideas can become recognized and adopted by anyone regardless of their background. In critical democracy, globalization is an assume context that should be embraced as it gives a field in which diversity of opinion and expression can grow. Hence, both critical democracy and neo-liberalism agree in the importance and value of globalization.

Finally, regardless of how important critical democracy may be in developing social justice and equality, there needs to be leaders and ordinary citizens in the society who actually practice it. The most effective way for a policy to become a reality is through strong leaders; without leaders in the education system that believe and practice critical democracy this whole discussion will have little effect on society.

\section{References}

[1] A. Gutmann, "Challenges of multiculturalism in democratic education", in A. Neiman (Ed.), Philosophy of Education Yearbook, 1995.

[2] Beattie, R.G., Ethics in deaf education, Academic press, 2001.

[3] Brenner, N.L., and N. Theodore, Space of Neoliberalism, Blackwell, 2002.

[4] Connell, R.W., School and social justice, Temple University Press, Philadelphia, 1993.

[5] G. Whitty, and Power, S, "Marketization and privatization in mass education systems", International Journal of Educational Development, 20, 2000, pp. 93107.

[6] Gidney, R.D., From hope to Harris, University of Toronto Press, Toronto Canada, 2002.

[7] J.A. Beane, and M.W. Apple, "The case for democratic schools", in M.W. Apple and J.A. Beane (Eds.), Democratic schools, ASCD, Alexandria VA, 1995, pp. 125.

[8] K. Osborne, "Democracy, democratic citizenship, and education", in J.P. Portelli and R.P. Solomon (Eds.), The erosion of democracy: From critique to possibility, Detselig Enterprises, Calgary Canada, 2001, pp. 29-62.

[9] L. Perry, "Conceptualizing Education Policy in Democratic Societies", Educational Policy, 23 (3), 2009, pp. 423-450. 
[10] Lambert, L.B., and A. Ochsner, Moment to Monument, Transaction publishers, 2009.

[11] M.W. Apple, "Understanding and interrupting Neoliberalism and Neoconservatism in Education", Pedagogies: An International Journal, 1 (1), 2006, 21-26.

[12] N. Gough, "Globalization and curriculum inquiry: Locating, representing, and performing a transnational imaginary", in N.P. Stromquist and K. Monkman (Eds.), Globalization and education: Integration and contestation across cultures, Rowman \& Littlefield Publishers, Lanham MA, 2000, pp. 77-98.

[13] R.D. Glass, "What is democratic education?", in W. Hare and J.P. Portelli (Eds.), Key questions for educators, Edphil Books, Halifax Canada, 2005, pp. 83-86.

[14] R.P. Solomon, and J.P. Portelli, "Introduction", in J.P. Portelli and R.P. Solomon (Eds.), The erosion of democracy: From critique to possibility, Detselig Enterprises, Calgary Canada, 2001, pp. 15-27.

[15] S. Ball, "What is policy? Texts, trajectories and tool boxes", Discourse, 13 (2), 1993, pp. 10-17.

[16] Sayed, F.H, Transforming Education in Egypt: Western influence and Domestic Policy Reform, The American University in Cairo Press, Cairo Egypt, 2006.

[17] Sehr, D.T., Education for public democracy, State University of New York Press, Albany NY, 1997.

[18] Stager, M.B., and R. Roy, Neo-liberalism a very short introduction, Oxford University Press, 2010.

[19] Taylor, S., F. Rizvi, B. Lingard, and M. Henry, Educational Policy and the Politics of Change, Routledge, London United Kingdom, 1997.

[20] W.C. Parker, "Advanced ideas about democracy: Toward a pluralist conception of citizen education", Teachers College Record, 98, 1996, pp. 104-125.

[21] White, G, The government and politics of Ontario, University of Toronto Press, 2001.

[22] Wiggan, G.A., and C. B. Hutchison, Global issues in education, Rowman and Littlefield education, 2009. 